\title{
Mitigating avian collision with power lines: a proof of concept for installation of line markers via unmanned aerial vehicle
}

\begin{tabular}{|r|l|}
\hline Journal: & Journal of Unmanned Vehicle Systems \\
\hline Manuscript ID & juvs-2015-0009.R2 \\
\hline Danuscript Type: & Article \\
\hline Complete List of Authors: & $\begin{array}{l}\text { Lobermeier, Scott; Colorado State University, Mechanical Engineering } \\
\text { Moldenhauer, Matthew; Colorado State University, Mechanical Engineering } \\
\text { Peter, Christophe; Colorado State University, Mechanical Engineering } \\
\text { Slominski, Luke; Colorado State University, Mechanical Engineering } \\
\text { Tedesco, Richard; EDM International, Inc., Engineering } \\
\text { Meer, Marcus; Colorado State University, Mechanical Engineering } \\
\text { Dwyer, James; EDM International, Inc., Environmental } \\
\text { Harness, Richard; EDM International, Inc., Environmental } \\
\text { Stewart, Andrew; EDM International, Inc., Engineering }\end{array}$ \\
\hline Keyword: & avian, collision, line marking, power line, UAV \\
\hline \multicolumn{2}{|l}{} \\
\hline
\end{tabular}


Mitigating avian collision with power lines: a proof of concept for installation of line markers via unmanned aerial vehicle

Scott Lobermeier, Matthew Moldenhauer, Christopher M. Peter, Luke Slominski, Richard A. Tedesco, Marcus Ver Meer, James F. Dwyer, Richard E. Harness and Andrew H. Stewart

Author affiliations:

\author{
S. Lobermeier, M. Moldenhauer, C. Peter, L. Slominski, R. Tedesco, and M. Ver Meer. \\ Engines and Energy Conversion Laboratory, Department of Mechanical Engineering, Colorado \\ State University, 430 N. College Ave. Fort Collins, CO 80524, USA.
}

J. F. Dwyer, R. E. Harness, A. H. Stewart, and R. Tedesco. EDM International Inc., 4001 Automation Way, Fort Collins, CO 80525, USA.

Corresponding author: J. Dwyer (e-mail: jdwyer@edmlink.com).

\begin{abstract}
Avian collisions with overhead power lines are a global conservation concern.
Collisions are mitigated primarily through marking power lines to increase the visibility of lines. Line marking is typically accomplished via an expensive and potentially dangerous process of hovering a helicopter within $1 \mathrm{~m}$ of a wire and installing line markers by hand. Unmanned Aerial Vehicles (UAVs) may offer a less dangerous, less costly alternative that is also less disturbing to wildlife. Herein we describe equipping a commercially available UAV with an installation arm
\end{abstract}


designed in collaboration with the Colorado State University Department of Mechanical Engineering to install line markers on a power line. The UAV installed line markers within a 30 $\mathrm{cm}$ target window on a model power line. The proof of concept described here demonstrates the potential utility of UAVs in mitigating avian collision with overhead power lines.

Key words: avian, collision, line marking, power line, remote-operated vehicle, UAV.

Résumé: French translation to be provided by the Journal of Unmanned Vehicle Systems.

\section{Introduction}

Avian collision with overhead power lines is an ongoing conservation concern (Quinn et al. 2011; Avian Power Line Interaction Committee [APLIC] 2012; Sporer et al. 2013). Power lines bisecting daily movement corridors between roosting and foraging sites have historically been most associated with collision (Bevanger and Brøseth 2004; Stehn and Wassenich 2008; APLIC 2012), with risk exacerbated by flocking behavior, low light, and inclement weather (Savereno et al. 1996; APLIC 2012; Hüppop and Hilgerloh 2012). Collision is most often documented where species with high wing loading, rapid flight speeds, and poor maneuverability are common (Shaw et al. 2010; Quinn et al. 2011; Barrientos et al. 2012). Thus, large, heavybodied water birds are generally thought to be more susceptible than smaller more maneuverable species (APLIC 2012), though this may be partly a function of detection (Rogers et al. 2015).

Collision risk also increases with increasing numbers of horizontal planes created by wires traversing avian flight paths (APLIC 2012). Avian collision has been reported primarily on transmission lines where birds appear to see and avoid large-diameter energized wires 
(conductors) by adjusting flight altitudes upward, but then collide with smaller, less visible overhead shield wires (Faanes 1987; Pandey et al. 2008; Murphy et al. 2009). For example, Faanes $(1987)$ reported that $91 \%(n=148)$ of observed transmission line collisions involved the overhead shield wire. Pandey et al. (2008) used Bird Strike Indicators (EDM International, Inc., Fort Collins, CO) to remotely monitor lines, and found $68 \%(n=154)$ of documented avian collisions involved the overhead shield wire. Murphy et al. (2009) reported 65\% $(n=71)$ of observed avian collisions involved overhead shield wires.

Proposed solutions have included modifying surrounding habitats, burying lines, removing overhead shield wires, and most commonly, marking wires to increase their visibility to birds. Modifying habitats can reduce an area's attractiveness to birds, thereby reducing local avian populations and avian collision risk. However, this approach is largely impractical because electric utilities rarely have influence over the use of land surrounding power lines. Burying transmission lines removes collision potential, but buried transmission lines experience substantially longer outages when damaged and cost roughly 10 times more to construct than overhead lines (Johnson 2004). This is true partly due to costs associated with preparing contingencies for contamination and ditching in sensitive habitats, and partly because buried lines require large cooling facilities (Johnson 2004). These factors render burying transmission lines economically infeasible in most applications. Removing overhead shield wires eliminates some collision potential, but the approach is precluded because overhead shield wires are critical to the reliability and overall safety of the overhead electric system (APLIC 2012). Consequently, collision mitigation typically focuses on marking lines.

Line markers are used to mitigate or reduce avian collision risk by increasing the visibility of overhead lines to birds (Beaulaurier 1981). The effect of marking lines varies by 
habitat, species, and season across studies (Bevanger and Brøseth 2004; Mojica et al. 2009;

Wright et al. 2009), but on average, line markers reduce collision rates by about 50\% (Brown and Drewien 1995; Murphy et al. 2009; Barrientos et al. 2011). Electric utilities typically install line markers on transmission lines by hand via helicopter hovering within $1 \mathrm{~m}$ of wires (Fig. 1). This approach maximizes efficiency, particularly because line marker manufacturers recognize installation efficiency as a critical design element, and as such they design markers that can be quickly installed this way. Nevertheless, operating helicopters in close proximity to power lines is dangerous, and has resulted in the deaths of helicopter pilots and crews (NTSB 1984, 2009, 2014).

Unmanned Aerial Vehicles (UAVs) can be effective in conducting environmental surveys (Chabot and Bird 2013; Martin 2014) and power line surveys (Li and Ruan 2010; Lobermeier et al. 2012; Mulero-Pázmány et al. 2014). We hypothesized that UAVs may also offer a safer, less expensive, and more flexible alternative for installing line markers. As a proof of concept to evaluate our hypothesis, we combined a commercially available UAV with an installation arm designed in partnership with the Colorado State University Department of Mechanical Engineering to develop a UAV capable of installing line markers on overhead shield wires.

\section{Materials and methods}

To ensure effectiveness, competing UAVs must be carefully compared prior to integration with a wildlife conservation program (Martin 2014). UAVs are commonly expected to maneuver precisely, record live video during flights, and maximize battery life aloft (Chabot and Bird 2013; Gibbens 2014). UAVs are not commonly expected to remotely deploy a static load at a precise location aloft. Thus, our application required a unique UAV capable of serving 
as a stable platform for a novel installation arm, and capable of compensating for changes in the vehicle's total mass when the line marker was installed.

We used a Mikrokopter Hexa XL (hereafter Microkopter; Moormerland, Germany) to develop the proof of concept described here (Fig. 2). The Microkopter's size (945 cm wide) and 6-rotor design provided a stable platform to carry the battery, camera, installation arm, and line marker needed for 15 minutes of operation in a $15 \mathrm{kph}$ crosswind, engineering parameters defined as necessary for practical use in field settings (Lobermeier et al. 2012). Onboard electronics included 3-axis gyroscopes and accelerometers capable of stabilizing the UAV within $1 \mathrm{~m}$ of an overhead shield wire in a computer-assisted hover. The Microkopter's load-mounting system designed to support a digital single lens reflex camera also provided an ideal foundation for anchoring the line marker installation arm to the airframe. An integrated GPS receiver enabled the Microkopter to return autonomously to a launch location in the event of an emergency, and its six rotors provided redundant control available to navigate safely if a rotor failed or if crosswinds exceeded the anticipated operating range.

We used a Spectrum (Champaign, IL, USA) DX8, 8 channel radio control transmitter to pilot the Microkopter. This multi-channel control system ensured that ambient radio signals would not interfere with operation of the Microkopter. We used a KX 171 Microcam (Moormerland, Germany) to provide live first-person video for pilots operating the Microkopter from a laptop computer. This feature ensured pilots had direct control at all times, allowing pilots to react immediately to environmental variation such as crosswinds or line elevation above ground level.

We used a BirdMark BM-AG (P\&R Tech, Beaverton, OR, USA) line marker in our proof of concept because the spring operation of the clamping mechanism could be pre-loaded to 
minimize installation forces on the UAV and the OHS (Fig. 3). This spring loaded device facilitated near-instantaneous (see results) installation when placed in contact with an overhead shield wire. We designed a lever-operated installation arm from a square fiberglass tube, selected for light weight, low cost, low conductivity, and high strength. We manufactured all other components from molybdenum disulfide-filled nylon plastics, and used commercially available hardware to connect manufactured components.

We determined a priori that we would consider our proof of concept successful if a line marker could be installed via the UAV within a $30 \mathrm{~cm}$ target window. We chose a $30 \mathrm{~cm}$ target window because regular spacing of line markers is typically emphasized in studies of line marker effectiveness (e.g., Sporer et al. 2013). To test our proof of concept, we assembled a model power line $3 \mathrm{~m}$ long and installed the line marker on this model.

\section{Results}

Our proof of concept was successful, installing a line marker on an outdoor mock power line within a $30 \mathrm{~cm}$ target window on a model overhead shield wire (Fig. 4). Achieving this goal required approximately 10 iterations as we fined tuned the installation arm to work with the line marker as intended. The total mass of our UAV was $2369 \mathrm{~g}$ (1200 g Microkopter, $975 \mathrm{~g}$ installation arm, $22 \mathrm{~g}$ microcam, and $172 \mathrm{~g}$ line marker). The UAV applied only $140 \mathrm{~g}$ of force to the line when installing line markers, much less than the wind loads lines are designed to withstand. Installation times were minimal. From arrival at the site, we required approximately 10 minutes to unpack the UAV, activate all systems, and mount a line marker on the deployment arm. An additional minute was required to fly the UAV into position, and then $<1$ second passed during installation. Subsequent cycles of loading and installing individual line markers could 
occur within 2-3 minutes, up to 5 cycles prior to a 5-minute pause to change batteries in the UAV.

Schematic line drawings of all components of the installation arm are available by contactingedm@edmlink.com.

\section{Discussion}

The proof of concept demonstrates the potential utility of UAVs designed to mitigate avian collision with overhead power lines. Given the widespread use of line marking in North America (Murphy et al. 2009; Quinn et al. 2011; Sporer et al. 2013), Europe (Bevanger and Brøseth 2004; Rollan et al. 2010; Barrientos et al. 2012), and Africa (Martin and Shaw 2010; Shaw et al. 2010), using UAVs to mark lines has potential global implications to conservation and management, helping to reduce the number of avian collisions occurring annually worldwide.

Safety is a key consideration when using full-sized helicopters to install line markers. Flight personnel can be lost to accidents, and lines can be damaged. Use of a UAV removes personnel from airborne operations, reducing risk of injury or fatality, and replaces the large steel rotors of a full sized helicopter with small plastic rotors of a UAV. This change eliminates risks of damaging lines during installation, effectively removing the two greatest inhibiting factors under consideration when deciding whether to mark a line. Full-size helicopters can facilitate faster installation of line markers once the aircraft and refueling truck are in place, but can require weeks of travel to fly the helicopter from its base to the power line, to drive the refueling truck from base to power line, and to return to base thereafter. Thus, though our UAV may not 
improve efficiency during the act of installing line markers, overall time, expense, and planning required likely would be reduced.

The design parameters of our UAV also make it ideal for conducting close evaluations of overhead power line structures (Lobermeier et al. 2012). These structures require regular surveys to evaluate potential operational and maintenance concerns before these concerns develop into unplanned emergencies (Li and Ruan 2010; Dwyer and Leiker 2012). However, improvements to our design to reduce weight and improve durability are needed prior to practical widespread use. Weight reduction would allow longer flight times for each battery, reducing delays related to changing and charging batteries, and reducing the number of batteries needed to power the UAV throughout a work day. Improving durability, particularly by protecting rotors with shrouds, would minimize the risk that damage to rotors might undermine the efficiency and cost effectiveness of using UAVs for line marking.

UAVs are less expensive and safer to operate than full sized-helicopters (Lobermeier et al. 2012; Martin 2014). With a total cost of approximately $\$ 3,000$ U.S. dollars, we anticipate an approximately $90 \%$ reduction in the total cost of installing line markers if this proof of concept is widely adopted. This would dramatically reduce the budgets needed to mark lines, and increase the number of line spans that could be marked within specific budgets. Though UAVs can disturb wildlife, when used responsibly, a UAV may be less likely to disturb wildlife than a fullsized helicopter (Martin 2014) while installing line markers. Despite these advantages, application of UAVs to wildlife conservation is limited by uncertainty in governmental regulations (Guglieri et al. 2014). Commercial organizations seeking to operate UAVs in the U.S. must file a petition with the FAA pursuant to Section 333 of the FAA Modernization and Reform Act of 2012 (FAA 2012) seeking exemption from requirements prohibiting use of 
UAVs. Once granted an exemption, a petitioner must then request and be granted a Certificate of Authorization (COA) for specific flight operations. Regulations are evolving at local and national levels (Martin 2014) and although the proof of concept illustrated here was successful, practical applications are unlikely until consistent and efficient regulations are developed for commercial applications.

\section{Acknowledgements}

This work was inspired by B. Wilson's Engineering Design course in the College of Engineering at Colorado State University (Fort Collins, CO, USA). We thank Z. Morozoko for helping organize the course. Funding provided by EDM International, Inc. (EDM; Fort Collins, CO, USA), GoPro (San Mateo, CA, USA), and Wolf Robotics, LLC (Fort Collins, CO, USA).

Figures by H. Bates (EDM), D. Bihn (Colorado State University) and J.F. Dwyer (EDM).

\section{References}

Avian Power Line Interaction Committee [APLIC]. 2012. Reducing avian collisions with power lines: the state of the art in 2012. Edison Electric Institute and Avian Power Line Interaction Committee, Washington, D.C., USA.

Barrientos, R., J.C. Alonso, C. Ponce, and C. Palacín. 2011. Meta-analysis of the effectiveness of marked wire in reducing avian collisions with power lines. Conserv. Biol. 25:893-903.

Barrientos, R., C. Ponce, C. Palaćin, C.A. Martín, B. Martín, and J.C. Alonso. 2012. Wire marking results in a small but significant reduction in avian mortality at power lines: a BACI designed study. PLoS ONE 7:1-10. 
Beaulaurier, D.L. 1981. Mitigation of bird collisions with transmission lines. Bonneville Power Administration. Portland, OR.

Bevanger, K., and H. Brøseth. 2004. Impact of power lines on bird mortality in a subalpine area. Biodivers. Conserv. 27:67-77.

Brown, W.M., and R.C. Drewien. 1995. Evaluation of two power line markers to reduce crane and waterfowl mortality. Wildlife Soc. B. 23:217-227.

Chabot, D., and D.M. Bird. 2013. Small unmanned aircraft: precise and convenient new tools for surveying wetlands. J. Unmanned Veh. Syst. 1:15-24.

Dwyer, J.F., and D.L. Leiker. 2012. Managing nesting by Chihuahuan ravens on H-frame electric transmission structures. Wildlife Soc. B. 36:336-341.

FAA (Federal Aviation Administration). 2012. FAA modernization and reform act of 2012.

FAA, Washington D.C. Available online at: https://www.faa.gov/uas/media/Sec_331_336_UAS.pdf.

Faanes, C.A. 1987. Bird behavior and mortality in relation to power lines in prairie habitats. Fish and Wildlife Technical Report 7. United States Department of the Interior, Publications Unit, Fish and Wildlife Service, Washington, DC.

Gibbens, D. 2014. Integrating UAS into the oil and gas industry. J. Unmanned Veh. Syst. 2:vivii.

Guglieri, G., F. Quagliotti, and G. Ristorto. 2014. Operational issues and assessment of risk for light UAVs. J. Unmanned Veh. Syst. 2:119-129.

Hüppop, O., and G. Hilgerloh. 2012. Flight call rates of migrating thrushes: effects of wind conditions, humidity and time of day at an illuminated offshore platform. J. Avian Biol. 43:85-90. 
Johnson, B. 2004. Out of sight, out of mind? A study on the costs and benefits of undergrounding overhead power lines. Edison Electric Institute, Washington, D.C.

Li, Z., and Y. Ruan. 2010. Autonomous inspection robot for power transmission lines maintenance while operating on the overhead ground wires. Int. J. Adv. Robot. Syst. $7: 107-112$.

Lobermeier, S., M. Moldenhauer, C. Peter, L. Slominski, R. Tedesco, and M. Ver Meer. 2012. Final report CSU unmanned aerial vehicle. Department of Mechanical Engineering, Colorado State University, Fort Collins, CO USA.

Martin, C. 2014. The drone debate: the intersection of drone technology and wildlife work. Wildlife Prof. 8:18-23.

Martin, G.R., and J.M. Shaw. 2010. Bird collisions with power lines: failing to see the way ahead? Biol. Conserv. 143:2695-2702.

Mojica, E.K., B.D. Watts, J.T. Paul, S.T. Voss, and J. Pottie. 2009. Factors contributing to bald eagle electrocutions and line collisions on Aberdeen Proving Ground, Maryland. J. Raptor Res. 43:57-61.

Mulero-Pázmány, M., J.J. Negro, and M. Ferrer. 2014. A low cost way for assessing bird risk hazards in power lines: Fixed-wing small unmanned aircraft systems. J. Unmanned Veh. Syst. 2:5-15.

Murphy, R.K., S.M. McPherron, G.D. Wright, and K.L. Serbousek. 2009. Effectiveness of avian collision averters in preventing migratory bird mortality from powerline strikes in the central Platte River, Nebraska. Final Report to the U.S. Fish and Wildlife Service, Grand Island, Nebraska, USA.

National Transportation Safety Board (NTSB). 1984. Safety recommendation(s) A-84-67 and - 
68. Washington, D.C.

National Transportation Safety Board (NTSB). 2009. National transportation safety board factual report aviation: NTSB ID: ERA09LA139. Washington, D.C.

National Transportation Safety Board (NTSB). 2014. Aviation accident database and synopses. Washington, D.C. http://www.ntsb.gov/_layouts/ntsb.aviation/index.aspx. Accessed 29 January 2014.

Pandey, A., R.E. Harness, and M.K. Schriner. 2008. Bird strike indicator field deployment at the Audubon National Wildlife Refuge in North Dakota: phase two. California Energy Commission, Public Interest Energy Research energy-related environmental research program, CEC-500-2008-020, Sacramento, CA.

Quinn, M., S. Alexander, N. Heck, and G. Chernoff. 2011. Identification of bird collision hotspots along transmission power lines in Alberta: an expert-based geographic information system (GIS) approach. J. Env. Inform. 18:12-21.

Rogers, A.M., M.R. Gibson, T. Pockette, J.L. Alexander, and J.F. Dwyer. 2015. Scavenging of migrant carcasses in the Sonoran Desert. Southwestern Nat. 59:in press.

Rollan, A., J. Real, R. Bosch, A. Tinto, and A. Hernandez-Matias. 2010. Modelling the risk of collision with power lines in Bonelli's eagle Hieraaetus fasciatus and its conservation implications. Bird Conserv. Int. 20:279-294.

Savereno, A.J., L.A. Savereno, R. Boettcher, and S.M. Haig. 1996. Avian behavior and mortality at power lines in coastal South Carolina. Wildlife Soc. B. 24:636-648.

Shaw, J.M., A.R. Jenkins, J.J. Smallie, and P.G. Ryan. 2010. Modelling power-line collision risk for the blue crane Anthropoides paradiseus in South Africa. Ibis 152:590-599. 
Sporer, M.K., J.F. Dwyer, B.D. Gerber, R.E. Harness, and A.K. Pandey. 2013. Marking power lines to reduce avian collisions near the Audubon National Wildlife Refuge, North Dakota. Wildlife Soc. B. 37:796-804.

Stehn, T.V., and T. Wassenich. 2008. Whooping crane collisions with power lines: an issue paper. Proceedings of the North American Crane Workshop 10:25-36.

Wright, G.D., T.J. Smith, R.K. Murphy, J.R. Runge, and R.R. Harms. 2009. Mortality of cranes (Gruidae) associated with powerlines over a major roost on the Platte River, Nebraska. Prairie Nat. 41:116-120. 


\section{Figure Captions}

Figure 1. Traditional dangerous and expensive installation procedure for line markers designed to mitigate avian collisions with overhead shield wires.

Figure 2. Unmanned Aerial Vehicle (UAV) with installation arm designed to install line markers on overhead shield wires.

Figure 3. Line marker installed on model overhead shield wire by Unmanned Aerial Vehicle (UAV).

Figure 4. Line drawing illustrating action of installation arm. 


\section{Figures}

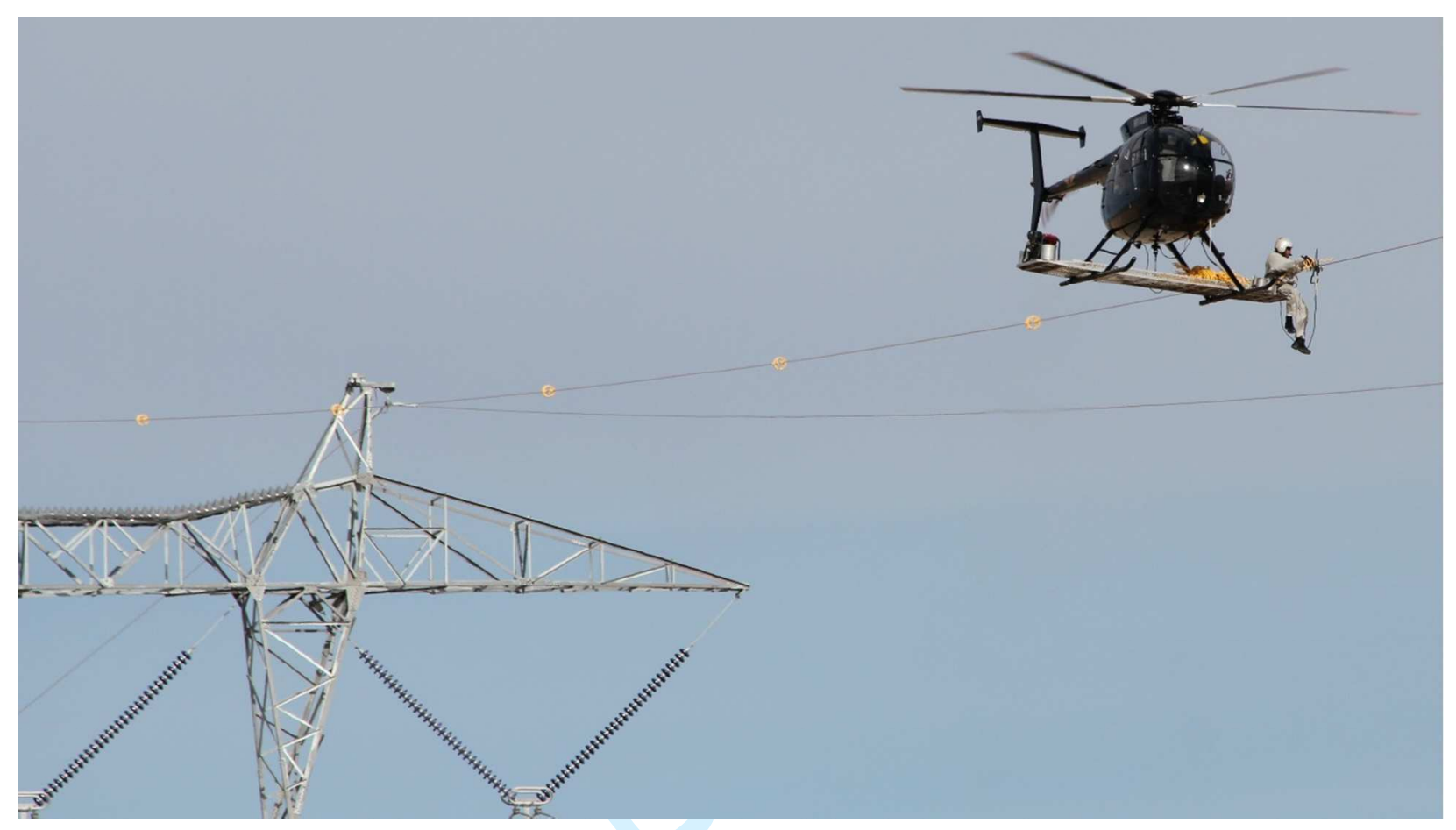

Figure 1. 


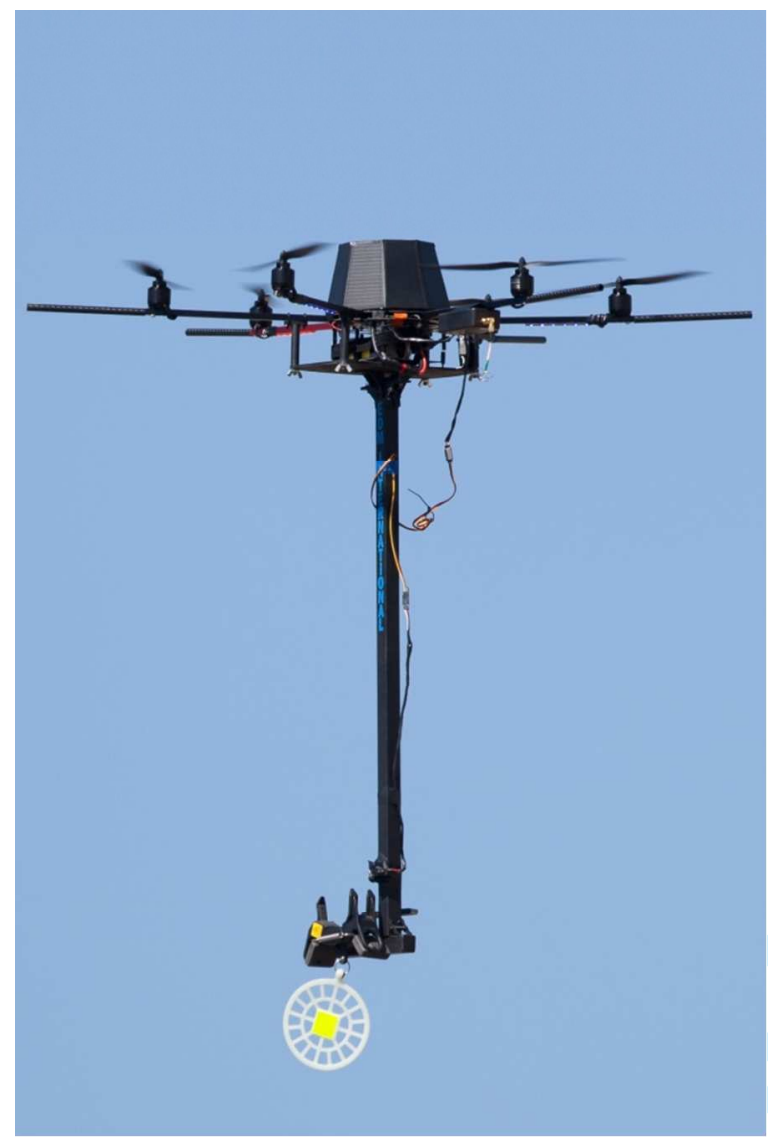

Figure 2. 


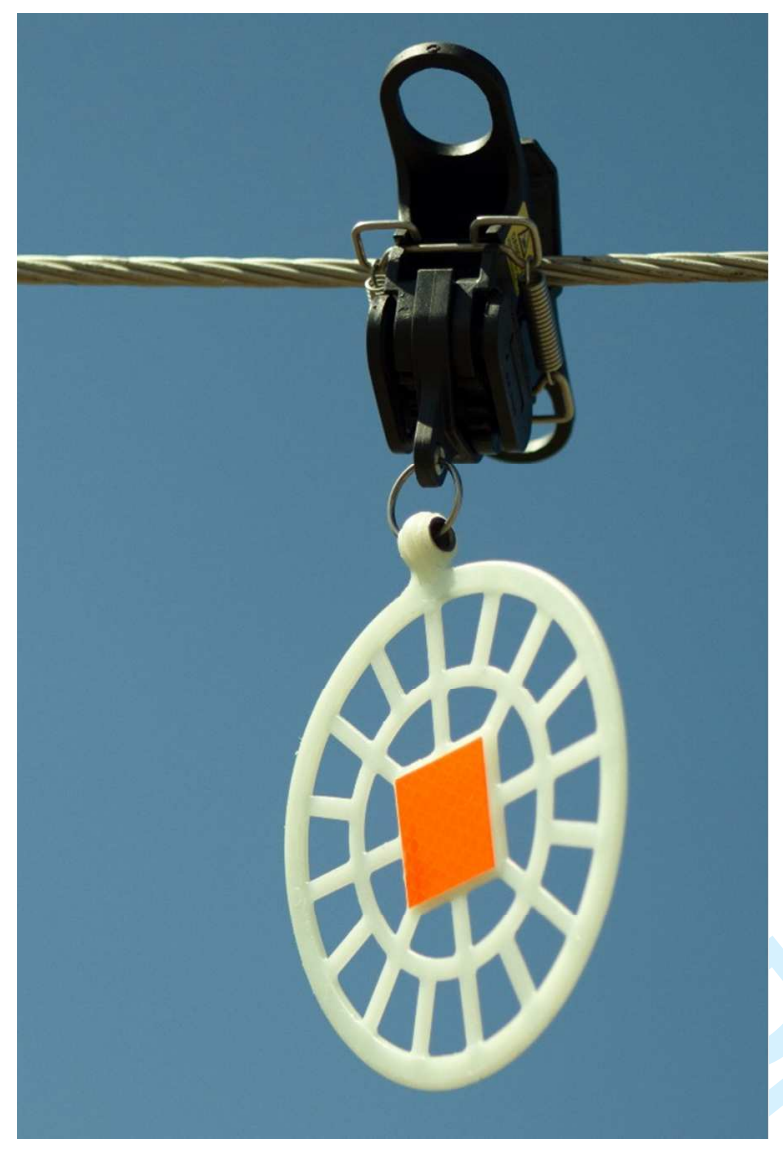

Figure 3. 


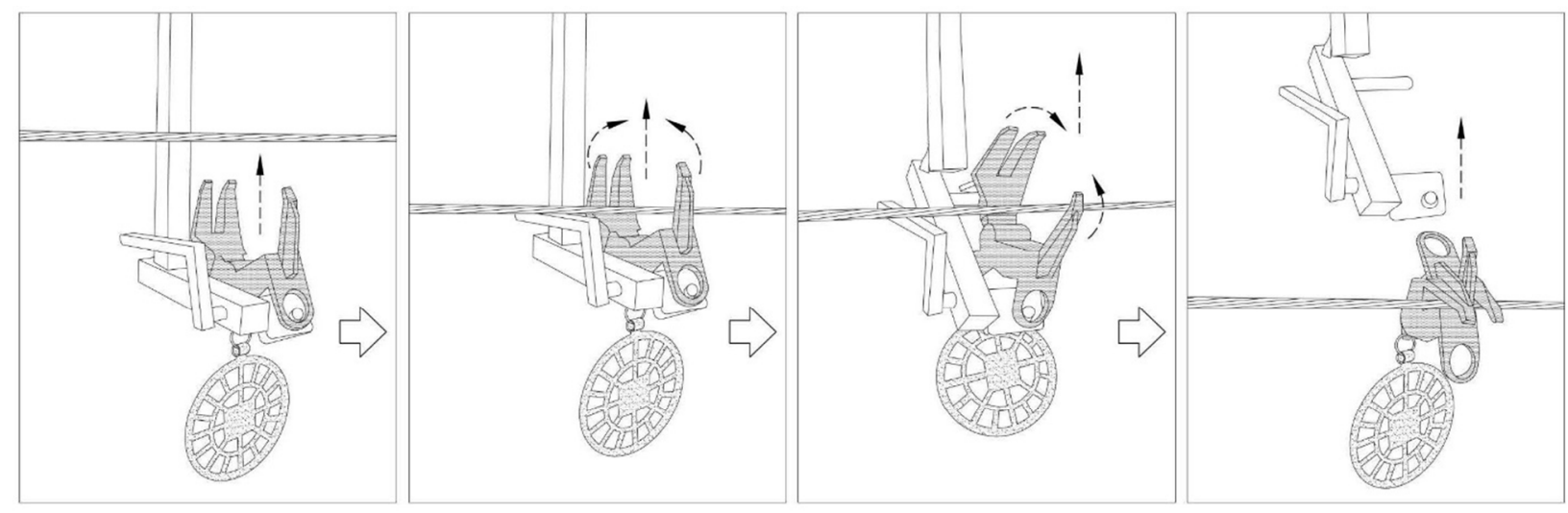

Figure 4. 